\title{
Semivolatile organic compounds removal and health risk reduction in drinking water treatment biofilters applying different backwashing strategies
}

\author{
Y. Chen $\cdot$ X. X. Zhang $\cdot$ B. Wu $\cdot$ B. Liu $\cdot$ \\ L. Xiao $\cdot$ A. Li $\cdot$ S. Cheng
}

Received: 3 April 2011/Revised: 18 August 2011/Accepted: 23 November 2011/Published online: 4 May 2012

(C) CEERS, IAU 2012

\begin{abstract}
This study aimed to investigate the removal of 24 semivolatile organic compounds in Yangtze River (China) source water treated by six biofilters using different backwashing methods. Health risks induced by the pollutants in the influent and effluent water were also assessed based on the chemical detections. Comparatively, the biofilter backwashed with both air $(15 \mathrm{~m} / \mathrm{h}, 3 \mathrm{~min})$ and water $(8 \mathrm{~m} / \mathrm{h}$, $5 \mathrm{~min}$ ) was most efficient in removing semivolatile organic compounds and reducing health risk. PCR-denatured gradient gel electrophoresis showed that backwashing alterations posed considerable influences on microbial community structure in the six biofilters. About $72.4 \%$ of di-n-butyl phthalate and $81.8 \%$ of bis(2-ethylhexyl)phthalate (two main semivolatile organic compounds in the river water) were removed under the optimal backwashing conditions. However, in the effluent of each biofilter, non-carcinogenetic risks of 2,6-dinitrotoluene and bis[2-ethylhexyl]phthalate and carcinogenetic risks of dibenz[a,h]anthracene and benzo[a]pyrene did not reach safety levels, revealing that these pollutants in the source water deserve more public health concerns. This study might serve as a basis for biofiltration process optimization and also as a benchmark for the authorities to reduce the health risk induced by exposure to the hazardous pollutants.
\end{abstract}

\footnotetext{
Y. Chen $\cdot$ X. X. Zhang $(\square) \cdot$ B. Wu $\cdot$ B. Liu $\cdot$ L. Xiao

A. Li $\cdot$ S. Cheng

State Key Laboratory of Pollution Control and Resource Reuse,

School of the Environment, Nanjing University,

Nanjing 210046, China

e-mail: zhangxx@nju.edu.cn

S. Cheng

e-mail: chengsp@nju.edu.cn

Y. Chen

Jiangsu Environmental Industry Co. Ltd, Nanjing 210019, China
}

Keywords Biological filtration - Drinking water contamination · Operational optimization · Public health

\section{Introduction}

Yangtze River is the longest river in Asia and drains onefifth of China's land area. The river basin containing onethird of China's population is one of the fast developing regions of China. Yangtze River is being used as drinking water source for most of the people living in the basin. However, the region is suffering from enormous environmental deterioration along with rapid industrialization. Recently, various semivolatile organic compounds (SVOCs), including polycyclic aromatic hydrocarbons ( $\mathrm{Xu}$ et al. 2001), polychlorinated biphenyls (Sun et al. 2002) and environmental endocrine disruptors (Wu et al. 2009b), have been detected in the water of Yangtze River, which is possibly threatening the safety of the drinking water supplied for the people living along the river. Therefore, these chemicals have to be effectively removed from drinking water in this region to reduce potential public health risk.

Biofiltration has been widely used in drinking water treatment for the removal of organic pollutants (Ifelebuegu 2011; Kim 2009). This technique enhances biological substrate removal by providing a surface for indigenous water microorganisms to attach and grow. Compared to conventional sand filtration, granular activated carbon (GAC) biofilters often shows higher efficiencies (Chien et al. 2006) due to effective bioadsorption and biodegradation in these biofilters, since dissolved oxygen is sufficient for the microorganisms (Zhang et al. 2010). However, biofilter performance is affected by various factors including temperature (Fazaelipoor 2010), substrate (Rene et al. 2008; Yu et al. 2009), hydraulic loading (Hassan and Sorial 2010; 
Zhang et al. 2010) and filter media (Liu et al. 2001). Recent studies have focused on the regulation and optimization of operational biofiltration conditions so as to improve removal efficiency of pollutants in wastewater (Spagni et al. 2010) or drinking water treatment (Devi et al. 2008).

Frequent water or air backwashing can remove loosely attached large microbial aggregates in favor of dead cells removal and microbial community stabilization (Bai et al. 2005; Choi et al. 2007). However, limited information is available about the influence of backwashing strategy selection on the removal of SVOCs in drinking water treatment biofilters and reduction of health risks induced by the hazardous substance.

This study investigated the removal of 24 SVOCs in Yangtze River source water treated by six biofilters applying different backwashing strategies. The biofilters were continuously operated at Beihekou Tap Water treatment Plant (Nanjing, China) during April to November of 2009 and the water and GAC samples were collected and transported to Nanjing University (China) for chemical analyses and biodiversity investigations. The induced noncarcinogenic and carcinogenic risks were assessed for the SVOCs in influent and effluent water of the biofilters. This study might serve as a basis for regulation and optimization of biofiltration process and also as a benchmark for the authorities to control health risk induced by exposure to the hazardous pollutants in drinking water.

\section{Materials and methods}

\section{Biofilters}

For effective removal of SVOCs in source water, six biofilters, numbered from BF1 to BF6, were continuously run for more than 180 days at Beihekou Tap Water Plant. The main part of each biofilter was a transparent polyvinyl chloride column with an inner diameter of $10 \mathrm{~cm}$ and an effective height of $100 \mathrm{~cm}$. Detailed information about configuration and size of the biofilters was previously described (Zhang et al. 2009). Each filter was packed with GAC (2.3 L) supported by sand $(1.1 \mathrm{~L})$. The biofilters were fed with effluent water from a pilot-scale settling tank in Beihekou Tap Water Plant. During the start-up period, the filters were continuously and stably operated for more than 30 days with influent hydraulic loading rate at $1.5 \mathrm{~m} / \mathrm{h}$. In each biofilter, dissolved oxygen was kept at $2.7-2.9 \mathrm{mg} / \mathrm{L}$, and water temperature ranged from 22.5 to $26.9{ }^{\circ} \mathrm{C}$. During this period, the six biofilters had a similar performance and showed no significant difference in the removal of chemical oxygen demand $\left(\mathrm{COD}_{\mathrm{Mn}}\right)$, assimilable organic carbon (AOC), ammonia nitrogen $\left(\mathrm{NH}_{3}-\mathrm{N}\right)$, total nitrogen (TN) and total phosphorus (TP). In order to investigate the effects
Table 1 Backwashing strategies used in this study (applying different air or water flow rates and durations)

\begin{tabular}{llllll}
\hline Biofilter & \multicolumn{2}{l}{ Air backwashing } & & \multicolumn{2}{l}{ Water backwashing } \\
\cline { 2 - 3 } \cline { 5 - 6 } & $\begin{array}{l}\text { Flow } \\
(\mathrm{m} / \mathrm{h})\end{array}$ & $\begin{array}{l}\text { Duration } \\
(\mathrm{min})\end{array}$ & & $\begin{array}{l}\text { Flow } \\
(\mathrm{m} / \mathrm{h})\end{array}$ & $\begin{array}{l}\text { Duration } \\
(\mathrm{min})\end{array}$ \\
\hline BF1 & 15 & 3 & & - & - \\
BF2 & 35 & 5 & & - & - \\
BF3 & - & - & & 8 & 5 \\
BF4 & - & - & & 15 & 8 \\
BF5 & 15 & 3 & & 8 & 5 \\
BF6 & 35 & 5 & & 15 & 8 \\
\hline
\end{tabular}

of backwashing on biofilter performance and SVOCs removal, different backwashing strategies were applied in the six biofilters (Table 1). Air backwashing (in BF1 and $\mathrm{BF} 2$ ) and water backwashing (in BF3 and BF4) were used to prevent clog of the biofilters. A combined backwashing method using air followed by water was employed in BF5 and BF6. After the backwashing alterations, the treatment systems ran stably for more than 5 weeks.

Water quality assessment

During the experimental periods, water samples were collected every $24 \mathrm{~h}$ from both influent and effluent of the six biofilters for the measurement of $\mathrm{COD}_{\mathrm{Mn}}, \mathrm{AOC}, \mathrm{NH}_{3}-\mathrm{N}$, $\mathrm{TN}$ and TP. $\mathrm{COD}_{\mathrm{Mn}}$ was measured using the acid-potassium permanganate method (NEPAC 2002). $\mathrm{NH}_{3}-\mathrm{N}$, TN and TP were determined using the methods recommended by APHA (APHA 2005), and AOC was measured according to $\mathrm{Li}$ et al. (2004). GAC samples were also collected every $24 \mathrm{~h}$ at the sampling site of each column (30 $\mathrm{cm}$ above bed bottom) and biomass was measured according to $\mathrm{Yu}$ et al. (2002).

\section{SVOC measurement}

During the post-regulation period (5 weeks), influent and effluent water were sampled for SVOCs measurement at day 7, 14, 21, 28 and 35 (at the end of each backwashing interval). Water samples $(10 \mathrm{~L})$ were collected in brown glass bottles previously washed with detergent, followed by deionized water, $2 \mathrm{M}$ nitric acid, deionized water again and finally influent or effluent water. The water samples were then transferred to lab in an ice bath within $3 \mathrm{~h}$. The water samples were filtered onto cellulose ester filters $(0.45-\mu \mathrm{m}$ pore size) and kept at $4{ }^{\circ} \mathrm{C}$ until analyses of the 24 SVOCs listed in Table 2. Extraction of the SVOCs was conducted using the method recommended by EMC (2011). Guide DSQ II Single Quadrupole GC/MS (ThermoQuest, San Jose, USA) with selected ion monitoring mode was used to 
Table 2 Components in source water fed to the biofilters

\begin{tabular}{lclc}
\hline Component & Concentration & Component & Concentration \\
\hline $\mathrm{pH}$ & $7.8-8.0$ & Bis[2-ethylhexyl]phthalate (ng/L) & $535-1,098$ \\
$\mathrm{Ca}(\mathrm{mg} / \mathrm{L})$ & $25.8-33.7$ & Butyl benzyl phthalate (ng/L) & $10.3-20.8$ \\
$\mathrm{Mg}(\mathrm{mg} / \mathrm{L})$ & $4.7-6.2$ & Chrysene (ng/L) & $7.2-9.7$ \\
$\mathrm{Na}(\mathrm{mg} / \mathrm{L})$ & $8.1-12.9$ & Dibenz[a,h]anthracene (ng/L) & $8.6-17.0$ \\
$\mathrm{~K}(\mathrm{mg} / \mathrm{L})$ & $2.2-3.4$ & Diethyl phthalate (ng/L) & $7.0-25.9$ \\
$\mathrm{COD}$ & $\mathrm{Mn}(\mathrm{mg} / \mathrm{L})$ & Dimethyl phthalate (ng/L) & $55.3-150.9$ \\
$\mathrm{AOC}(\mathrm{mg} / \mathrm{L})$ & $2.55-3.61$ & Di- -butyl phthalate (ng/L) & $1,316-2,575$ \\
$\mathrm{NH}$ - $\mathrm{N}(\mathrm{mg} / \mathrm{L})$ & $0.38-0.62$ & $2,6-$ Dinitrotoluene (ng/L) & $201.3-541.1$ \\
$\mathrm{TN}(\mathrm{mg} / \mathrm{L})$ & $0.15-0.28$ & $2,4-$ Dinitrotoluene (ng/L) & $13.5-22.5$ \\
$\mathrm{TP}(\mathrm{mg} / \mathrm{L})$ & $0.66-1.08$ & Fluorene (ng/L) & $9.1-18.0$ \\
Acenaphthylene (ng/L) & $0.10-0.18$ & Hexachlorobenzene (ng/L) & $3.0-5.7$ \\
Anthracene (ng/L) & $5.3-12.2$ & Hexachlorocyclopentadiene (ng/L) & $8.9-13.4$ \\
Benzo[a]anthracene (ng/L) & $26.2-46.1$ & Indeno[1,2,3-cd]pyrene (ng/L) & $5.9-17.4$ \\
Benzo[a]pyrene (ng/L) & $11.8-20.9$ & Isophorone (ng/L) & $5.2-15.6$ \\
Benzo[b]fluoranthene (ng/L) & $7.4-14.2$ & Phenanthrene (ng/L) & $12.6-30.8$ \\
Benzo[k]fluoranthene (ng/L) & $9.6-19.9$ & Pentachlorophenol (ng/L) & $9.8-18.8$ \\
Bis[2-ethylhexyl]adipate (ng/L) & $12.8-19.1$ & Pyrene (ng/L) & $7.8-11.2$ \\
\hline
\end{tabular}

determine the concentrations according to $\mathrm{Wu}$ et al. (2009b). Quality assurances were preformed according to Wu et al. (2009a, b). Detection limits of the compounds ranged from 0.4 to $2 \mathrm{ng} / \mathrm{L}$ (a signal-to-noise ratio of 3 ).

\section{DNA extraction and PCR}

For microbial community structure analysis, total DNA was extracted from each GAC sample collected from the six biofilters at the 35th day after the backwashing regulation. GAC was vortexed for $10 \mathrm{~min}$ to separate bacterial cells. The liquid phase $(50 \mathrm{~mL})$ was centrifuged and the pellet was used for DNA extraction with Fast Soil Genome DNA Isolation Kit (Bioteke, China). Integrity of DNA was confirmed after electrophoresis on $0.8 \%$ agarose gels by comparison with DNA ladder ( $\lambda$ HindIII, Takara, Japan). Purity of the DNA was spectrophotometrically determined by the ratio of absorbance at 260 and $280 \mathrm{~nm}$. A 472 basepair hypervariable region of the $16 \mathrm{~S}$ rRNA gene was amplified by polymerase chain reaction (PCR). PCR primers and amplification conditions were previously described in detail (Zhang et al. 2010). Duplicate PCRs were carried out for each sample with sterile water as negative control, and PCR products were checked by electrophoresis on $1 \%$ agarose gel with ethidium bromide in $1 \times$ TAE buffer at $120 \mathrm{~V}$ for $15 \mathrm{~min}$.

DGGE and phylogenetic analysis

After 16S rRNA PCRs, denatured gradient gel electrophoresis (DGGE) was used to investigate microbial diversity in the biofilters. The DGGE assay was performed using Bio-Rad Dcode ${ }^{\mathrm{TM}}$ Gene Mutation Detection System (Bio-Rad, USA) following the method of Zhang et al. (2010). After electrophoresis, the desired bands were cut from the DGGE gel and DNA was recovered using PolyGel DNA Extraction Kit (Omega Co., USA). PCR product of each DNA fragment was purified using PCRquick spin $^{\mathrm{TM}}$ PCR Product Purification Kit (iNtRon Biotechnology Co., South Korea). The DNA fragments were cloned directly into pUCm-T vector using a TA cloning kit (Promega Co., USA). DNA sequencing was performed by automated means at Sangon (Shanghai, China) using M13 primer set. The 16S rRNA homology searches were conducted using the BLAST program at the National Centers for Biotechnology Information (National Institutes of Health, Bethesda, USA). Nucleotide sequences were aligned using the multiple sequence alignment program CLUSTAL W (Thompson et al. 1994). The GenBank sequences having the highest identity to those obtained in this study were retrieved for phylogenetic tree construction. Neighbor-joining trees were constructed using MEGA version 4.1 and bootstrap analysis with 1,000 replicates was performed to evaluate the significance of the nodes.

Health risk assessment

In order to further compare the performance of the biofilters, the induced health risks were assessed for the SVOCs in influent and effluent water. Health risk assessment was carried out on a basis of reliable exposure pathways of contaminants (USEPA 2011c). Exposure to the organic 
pollutants in drinking water was considered mainly via the following pathways: (a) direct ingestion of water consumption, and (b) dermal absorption of contaminants in water adhered to exposed skin. Carcinogenic and noncarcinogenic risks were assessed based on the two exposure pathways in this study. The assessment included exposure dose determination (ingestion and dermal absorption pathway), hazard quotient calculation, non-carcinogenic hazard index (HI) and carcinogenic target risk (TR) calculations, and uncertainty analysis. The assessment procedures and methods, as well as the mathematical models, were previously described in detail (Wu et al. 2010).

\section{Statistical analysis}

Experimental results were statistically analyzed using SPSS 11.0 (SPSS Inc., Chicago, USA). The least significant differences test was used to measure the differences of each water quality parameter, SVOC level and health risk among the six biofilters. An analysis of variance (ANOVA) test was carried out to assess the homogeneity of variance and $p<0.05$ was considered statistically significant.

Nucleotide sequence accession numbers

The sequences of 16S rRNA genes obtained in this study have been deposited in GenBank under accession No. HQ843996 to HQ844001.

\section{Results and discussion}

Pollutant removal performance of the six biofilters

Table 2 shows the concentrations of the components in the inlet water of the biofilters. During the start-up period (>30 days), the filters were operated continuously and stably with a water backwashing $(20 \mathrm{~m} / \mathrm{h}$ for $3 \mathrm{~min})$ interval at 7 days. Within this period, operational performance showed no significant difference in the removal of $\mathrm{COD}_{\mathrm{Mn}}(80.3 \pm 1.0 \%)$, AOC $(88.1 \pm 1.2 \%), \mathrm{NH}_{3}-\mathrm{N}$ $(66.6 \pm 0.8 \%), \quad \mathrm{TN}(58.8 \pm 0.9 \%)$ and $\mathrm{TP} \quad(78.2 \pm$ $1.6 \%)$. At the end of this period, backwashing conditions were altered in each biofilter, except for BF3 (Table 1). After water backwashing, intensity was increased to $15 \mathrm{~m} /$ $\mathrm{h}$ for $8 \mathrm{~min}$ in $\mathrm{BF} 4$; each removal of $\mathrm{COD}_{\mathrm{Mn}}, \mathrm{AOC}, \mathrm{NH}_{3}-\mathrm{N}$ and TN showed a significant decrease $(p<0.05)$ (Fig. 1a), revealing an evident effect of water backwashing intensity on biofilter performance.

Air backwashing also had a considerable influence on the removal of the pollutants. With weekly air backwashing at $15 \mathrm{~m} / \mathrm{h}$ for $3 \mathrm{~min}, \mathrm{BF} 1 \mathrm{had}$ high removal in $\mathrm{COD}_{\mathrm{Mn}}$, AOC, $\mathrm{NH}_{3}-\mathrm{N}, \mathrm{TN}$ and $\mathrm{TP}$, demonstrating that appropriate
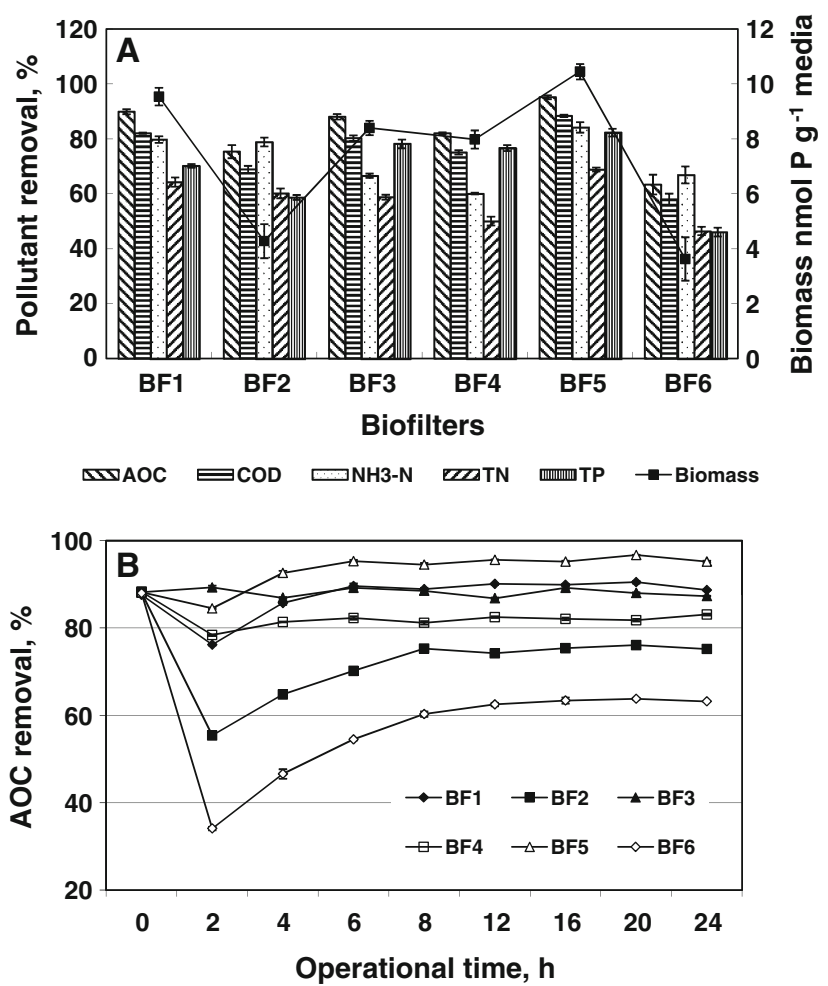

Fig. 1 Removal percentages of AOC (assimilable organic carbon), $\mathrm{COD}_{\mathrm{Mn}}$ (chemical oxygen demand $[\mathrm{Mn}]$ ), $\mathrm{NH}_{3}-\mathrm{N}$ (ammonia nitrogen), TN (total nitrogen) and TP (total phosphorus) in the six biofilters during the operation period ( $35 \mathrm{~d}$ ) after the backwashing alterations

air backwashing conditions contribute to microbial activity improvement in the biofilters (Fig. 1a). However, too high backwashing air flow in BF2 resulted in the decrease in microbial biomass and the pollutant removal (each $p<0.05)$. A combined backwashing using both water and air was applied for BF5 and BF6. Among the six biofilters, BF5 had the highest removal in each of $\mathrm{COD}_{\mathrm{Mn}}(88.4 \%)$, AOC (95.2\%), $\mathrm{NH}_{3}-\mathrm{N}(84.2 \%)$, TN (68.9\%) and $\mathrm{TP}$ $(82.3 \%)$ (each $p<0.05$ ), indicating that the combined backwashing method is more effective in pollutant removal compared with separate use of air or water. However, BF6 showed a very poor performance in pollutant removal, since too high backwashing intensity in the biofilter resulted in the low biomass (3.6 nmol P/g media) (Fig. 1).

These results have shown that GAC biofilter can serve as a cost-effective and environmentally friendly process for advanced drinking water treatment, which is supported by previous studies applying the process to remove organic carbon (Tian et al. 2009) and nitrogen (Zhang et al. 2010) in source water. Compared with other biological processes used for drinking water treatment, biofiltration (especially using GAC as media) enhances substrate removal by providing a surface for indigenous water microorganisms to attach and grow (Moll et al. 1998). Previous studies showed that over 
$80 \%$ of AOC could be removed in a pilot-scale GAC filtration process (Chien et al. 2006); while only $26.5 \%$ of total organic carbon was removed by sand filtration in 30 conventional drinking water treatment plants (Kim 2009).

Combined use of air $(15 \mathrm{~m} / \mathrm{h}$ for $3 \mathrm{~min})$ and water $(8 \mathrm{~m} / \mathrm{h}$ for $5 \mathrm{~min}$ ) was considered as the optimal backwashing method in this study. GAC biofilters accumulate both biological and non-biological particles on the filter bed, and intermittent backwashing is necessary for the biofilters to prevent clog. Some previous studies investigated the effects of backwashing alterations on biofilter performance (Liu et al. 2001; Zheng and Long 2008). Liu et al. (2001) has indicated that chlorine in backwashing water affects biofilter performance and GAC filters are more resistance to chlorinated backwashing water than anthracite filters. Zheng and Long (2008) revealed that a long backwashing interval ( $>20$ days) was practicable in an intermittent aerated biofilter developed for phosphorus removal in sewage. In this study, AOC removal (Fig. 1b) and microbial mass (Fig. 1c) in each biofilter were recovered within $24 \mathrm{~h}$ after backwashing, indicating that the backwashing intensities were acceptable for the biofilters. However, the backwashing alterations affected biomass increase and pollutant removal. AOC, COD and TP removal had positive correlations with biomass increase (each $p<0.05$ ), but nitrogen removal showed no correlation to the bacterial growth $(p>0.05)$. Although hydrophobic bacteria are more strongly attached to the GAC surface than hydrophilic particles (Ahmad and Amirtharajah 1998), air or water backwashing with too high intensity can detach active cells from the media surface to cause biomass decrease and microbial community damage.

\section{Effects of backwashing on removal of SVOCs}

This study investigated the changes of concentrations of 24 individual SVOCs in the biofiltration systems. Total concentration of the SVOCs in the inlet of the biofilters was determined to be 2,391-4,923 ng/L. These 24 SVOCs are divided into three groups, i.e., 12 polycyclic aromatic hydrocarbons (PAHs), six phthalates (PAEs), and six benzene derivatives or heterocycle compounds (BDHCs). The total influent concentrations of PAHs, PAEs and BDHCs were about $180,3,028$ and $419 \mathrm{ng} / \mathrm{L}$, respectively (Fig. 2). PAEs in Yangtze River source water had the similar level to those in Taiwan River (Yuan et al. 2002), while PAHs concentrations were lower than those in several of other Chinese rivers, including Minjiang River (Zhang et al. 2004), Qiantang River (Zhu et al. 2008) and Yellow River (Li et al. 2006). Among the 24 SVOCs, di- $n$-butyl phthalate $(1,946 \mathrm{ng} / \mathrm{L})$, bis(2-ethylhexyl)phthalate (817 $\mathrm{ng} / \mathrm{L})$ and 2,6-dinitrotoluene $(371 \mathrm{ng} / \mathrm{L})$ contributed most to the total concentration (Table 2).
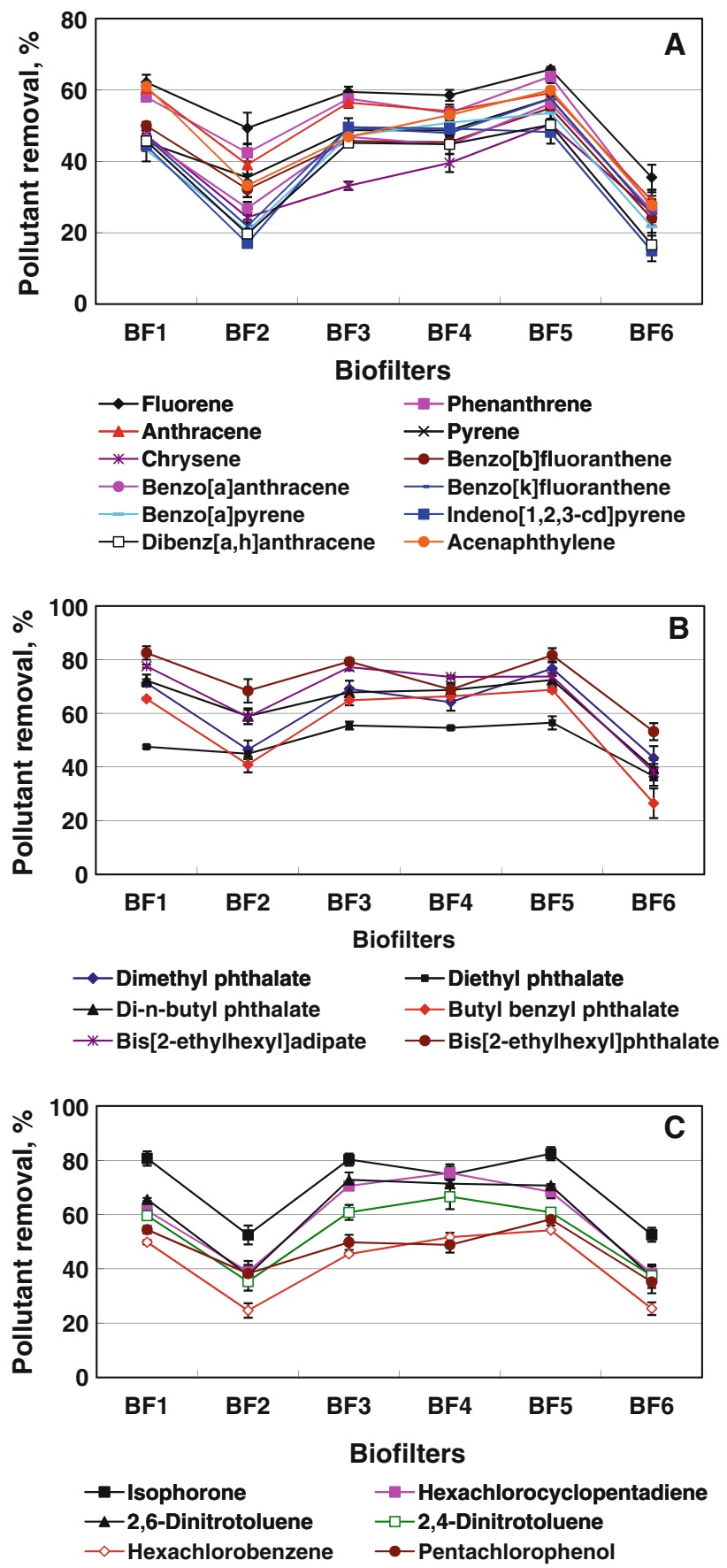

Fig. 2 Removal percentages of 24 semivolatile organic compounds, including 12 polycyclic aromatic hydrocarbons (a), six phthalates (b), and six benzene derivatives or heterocycle compounds (c), in the six biofilters applying different backwashing strategies

Backwashing alterations significantly influenced the removal of 24 SVOCs in the biofilters. Comparatively, BF5 had the highest removal in PAHs (56.4 \%), PAEs (71.6 \%) and BDHCs $(65.8 \%)$. BF2 and BF6 showed poor performance in SVOCs removal, indicating that high air flow hindered metabolism of the SVOCs by microorganisms in the biofilters (Fig. 2). However, BF3 and BF4 shared a 
similar removal performance, demonstrating that the water backwashing alteration posed a relatively slighter effect.

This study showed that PAHs were more redundant to ready microbial utilization than the other two groups (Fig. 2a), since these chemicals are composed of fused aromatic rings whose biochemical persistence arises from dense clouds of $\pi$-electrons on both sides of the ring structures making them resistant to nucleophilic attack (Zhang et al. 2006). However, biofilter cultivated with functional microorganisms can remove over $70 \%$ of benzo(a)pyrene in drinking water (Zhang et al. 2009). Among the PAHs, fluorene showed to be the most readily degraded (Fig. 2a). Comparatively, fluorene comprises fewer benzene rings and the carbon atom linking the two benzene rings in fluorene molecule is often attacked by the oxygen free radical to form 9-fluorenone under the catalysis of naphthalene 1,2-dioxy-genase, with a result that the two rings are easily divided under subsequent oxidation reactions (Zhang et al. 2006).

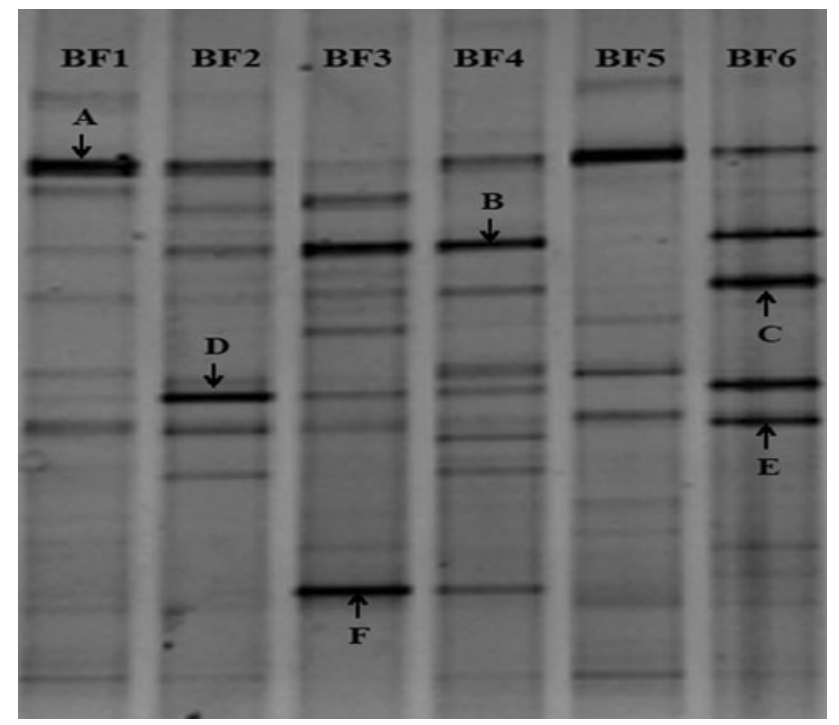

Fig. 3 Denaturing gradient gel electrophoresis (DGGE) analysis of PCR amplified 16S rRNA extracted from the media in the six biofilters (BF1-BF6)
Among the PAEs, di- $n$-butyl phthalate and bis(2-ethylhexyl)phthalate, the two main SVOCs in the influent water, showed the highest removal of 72.4 and $81.6 \%$ in BF5, respectively (Fig. 2b). Compared to PAHs and BDHCs, PAEs had relatively higher removal in the biofilters, because the linear structure of these molecules is more easily attacked by free radicals. Isophorone was metabolized more readily because a carbonyl group is located on the ring of the compound, which makes ring-opening to take place more easily (UM-BBD 2011). More than $70 \%$ of 2,6-dinitrotoluene was removed in each of BF3, BF4 and BF5, but the removal efficiency was lower than $37 \%$ in BF2 and BF6, further confirming the hypothesis that the biofilters are more sensitive to the air backwashing alteration. Information is limited about the removal of the SVOCs in biofilters, but it is known that biofilters are effective in removing volatile organic compounds (Lebrero et al. 2010; Rattanapan et al. 2010). Hassan and Sorial (2010) showed that the removal efficiency of benzene was $90 \%$ in a controlled trickle bed air biofilter at a loading rate of $64 \mathrm{~g} / \mathrm{m}^{3} / \mathrm{h}$.

Effects of backwashing on microbial community structure

In this study, 16S rRNA PCR-DGGE was used to differentiate the microbial community structures in the six biofilters with different backwashing strategies. A total of 12 bands were excised from the DGGE gel, out of which six yielded unanimous sequences (Fig. 3). By BLAST search algorithm, high similarity values were observed after DNA sequencing, and these results were confirmed by phylogenetic analysis (Fig. 4). Band A had $99 \%$ sequence similarity to an uncultured bacterial clone from activated sludge of wastewater treatment plants (GenBank accession No. AF495418.1) and band B was identified to be Shigella flexneri. Bands $\mathrm{C}, \mathrm{D}$ and $\mathrm{E}$ were nicely grouped together and belonged to Escherichia coli. DNA sequencing showed that band $\mathrm{F}$ was closely related to an uncultured bacterial clone (GenBank accession No. GQ485641.1) previously
Fig. 4 16S rRNA phylogenetic analysis of the dominant microbial species in the biofilters using the neighborjointing method (MEGA version 4.1). Bootstrap analysis with 1,000 replicates was used to evaluate the significance of the nodes. GenBank accession numbers of the sequences are given in parenthesis

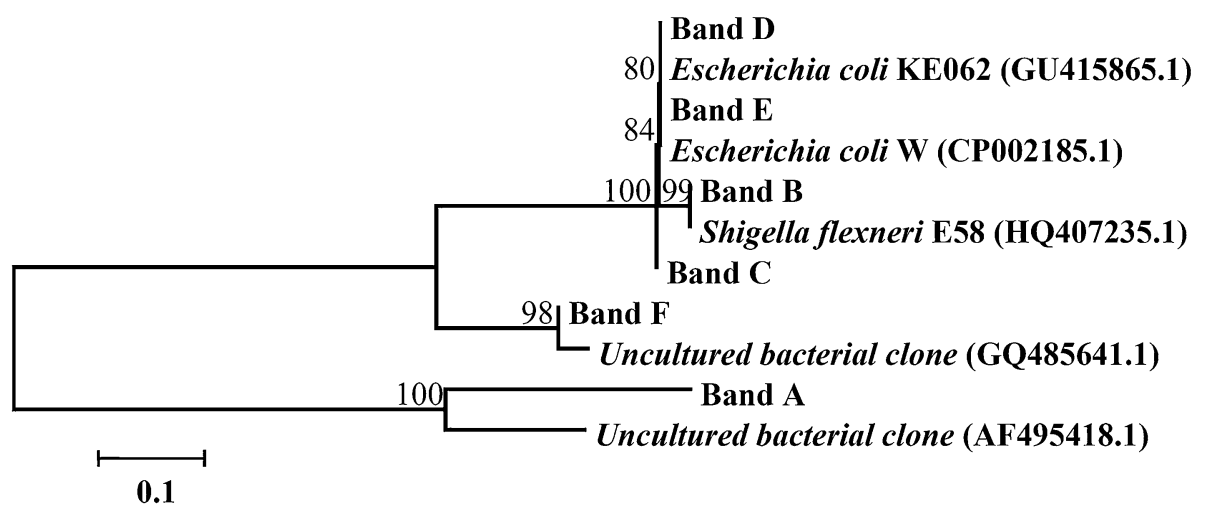


detected in drinking water treatment biofilters (Zhang et al. 2010).

Backwashing regulations posed obvious impacts on the microbial community structure in the biofilters. Band A was the dominant species in BF1 and BF2 (using air backwashing), while bands $\mathrm{B}$ and $\mathrm{F}$ appeared in the lanes of BF3 and BF4 (using water backwashing) and were very weak in the lanes of BF1 and BF2. E. coli represented by band $\mathrm{D}$ grew well in the biofilter with high air backwashing flow. The bacterial pattern in biofilter BF5 showed fewer intense bands, of which band A was sequenced and had a high identity of an uncultured bacterial strain from wastewater treatment plants (GenBank accession No. AF495418.1), suggesting that the species might be involved in the high pollutant removal efficiency in BF5. Shigella sp. (band B) was frequently detected in drinking water and is closely related to public health surveillance for various infectious diseases (Koutsotoli et al. 2006). E. coli is well known to have high detection frequency in drinking water (Juhna et al. 2007) and is capable of utilizing a variety of organic compounds including PAHs, phthalate, trinitrotoluene and heterocycle compounds (UM-BBD 2011). These dominant bacteria can secrete various biochemical enzymes with biodegradation function (Gonzalez-Perez et al. 2007), which might contribute to the removal of the SVOCs.

Previous studies showed that microbial community structures in biofilters could adapt to changing operational conditions, e.g., inlet loadings (Zhang et al. 2010) and substrates starvation (Moll et al. 1998). However, few investigations have been documented about the effect of backwashing on microbial community structure in biofilters. The alterations in air or water backwashing intensity control the biofilm formation, as well as microbial composition and activity in the biofilters (Liu et al. 2001). In turn, the microbial activity governs the substrate utilization performance of the biofilters (Moll et al. 1998).

Health risk induced by the SVOCs in influent and effluent

Non-carcinogenic and carcinogenic risk quotients of the SVOCs in the influent and effluent water were calculated to evaluate the potential health risk induced by these contaminants. Given that health risk analysis was performed only for the pollutants with available health guidelines, this study calculated the non-carcinogenic HI of 12 SVOCs (Table 3) and carcinogenic risk TR of other 12 SVOCs (Table 4). The SVOCs in the influent and effluent posed a slight adverse effect on pubic health because HI was lower than 1.0 (non-carcinogenic risk threshold) and TR was below $1.0 \times 10^{-6}$ (carcinogenic risk threshold) for most of the individual SVOCs via

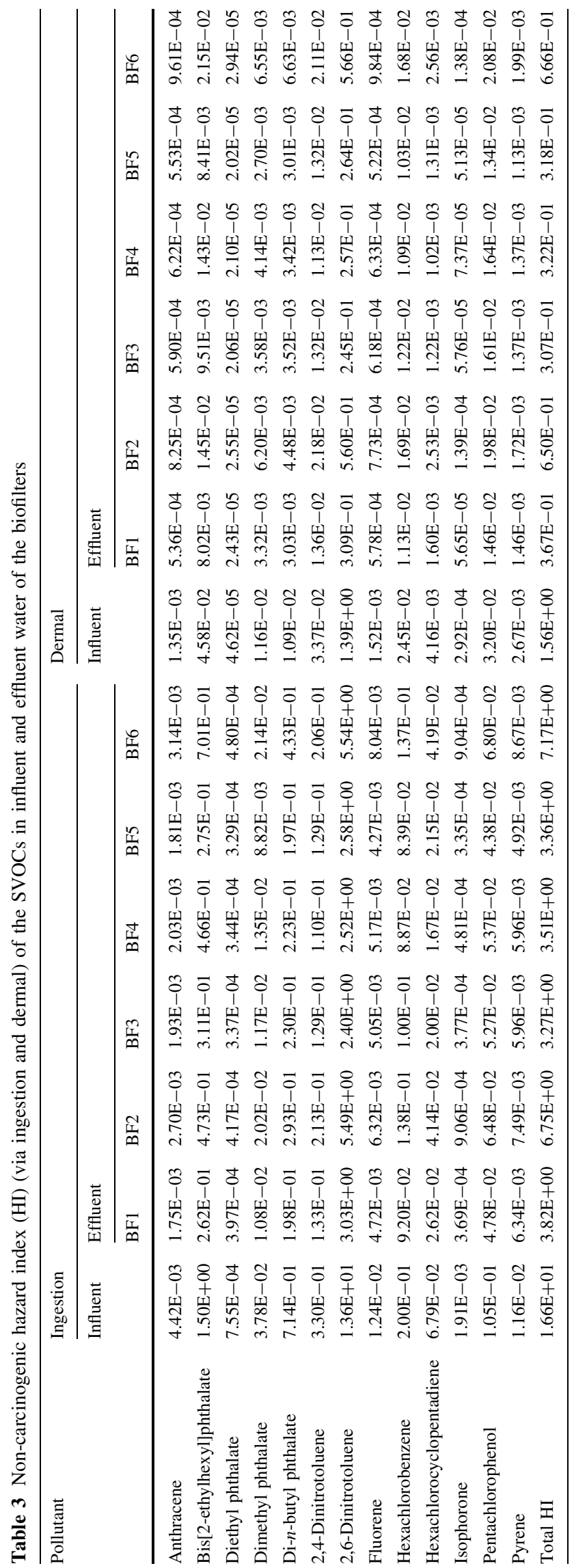




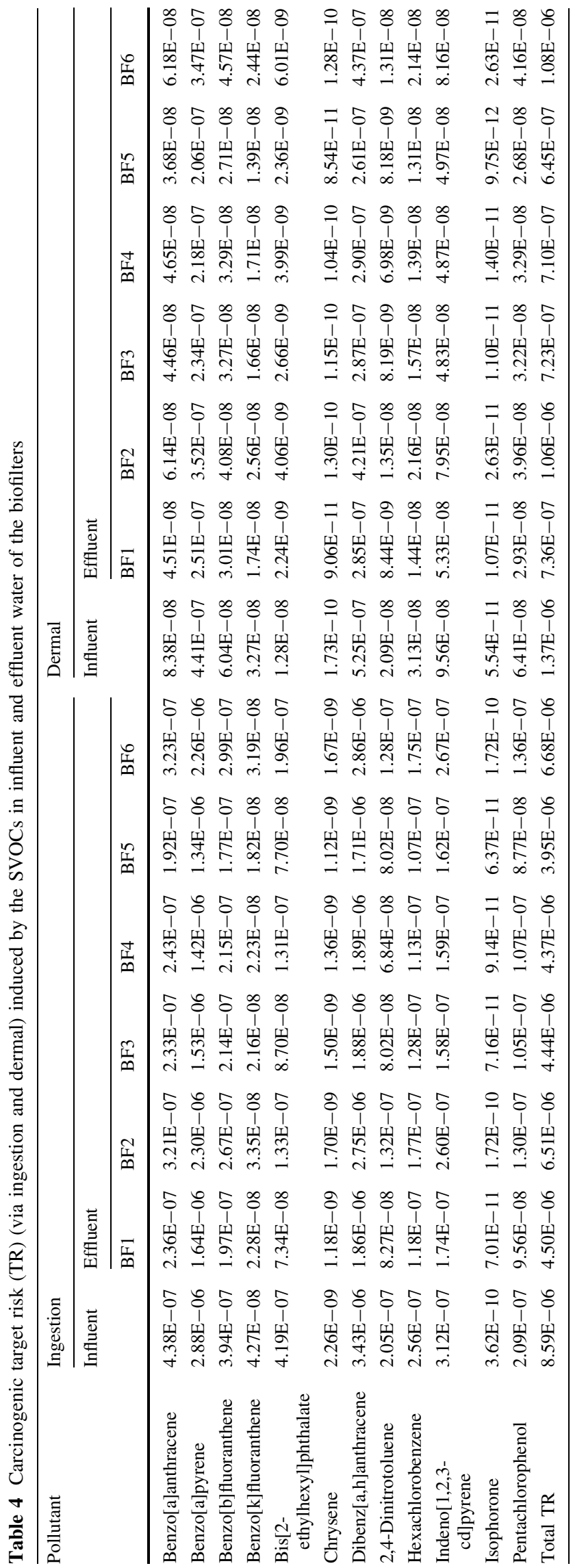

ingestion or dermal exposure (Table 3). However, exposure to influent 2,6-dinitrotoluene or bis[2-ethylhexyl] phthalate via ingestion can induce hazardous risk since the HI values were more than 1.0. Dermal exposure to 2,6-dinitrotoluene might also cause damages to human heath. High concentrations of the two chemicals in influent water may account for the higher non-carcinogenetic risks. Additionally, total HI and TR of the influent SVOCs were both higher than the threshold values, suggesting that the integrated risks induced by these chemicals deserve more concerns (Table 3).

Dibenz[a,h]anthracene and benzo[a]pyrene contributed most to the total carcinogenetic risk (Table 4), although concentrations of these two compounds were lower than most of the other SVOCs. Among PAHs, dibenz[a,h] anthracene and benzo[a]pyrene are well known to have the highest carcinogenetic risk (USEPA 2011b), and the carcinogenetic risk threshold is recommended as only 2.9 $\mathrm{ng} / \mathrm{L}$ for both the chemicals in drinking water (USEPA 2011a). Wu et al. (2010) indicated that the two contaminants in Yangtze River source water could induce potential carcinogenic effects under a worst-case scenario.

Biofilter backwashing alterations greatly influenced the reduction of the health risk induced by SVOCs. Comparison of total HI or TR showed that effluent from BF3, BF4 and BF5 induced relatively lower health risks, which is in accordance with the chemical detections (each $p<0.05$ ). Total dermal HI was evidently reduced to below 1.0 in each of the six biofilters, but the risk via ingestion was still more than the criteria for each filter effluent. Among the SVOCs, 2,6-dinitrotoluene contributed most to the total ingestion $\mathrm{HI}$. The effluent water from BF1, BF3, BF4 and BF5 had no dermal carcinogenetic risk, but each can cause potential carcinogenetic risk via ingestion, which mainly arose from dibenz[a,h]anthracene and benzo[a]pyrene in the water. This study showed that too high air backwashing flow posed a negative effect on the reduction of health risk induced by the SVOCs, evidenced by the relatively less risk reduction in BF2 and BF6. Water backwashing, or combined backwashing with water and air at an appropriate flow, was relatively more efficient in minimizing the heath risk.

\section{Conclusion}

This study revealed that backwashing significantly influenced biomass and microbial community structure and subsequently affected SVOCs removal and health risk reduction in biofilters. Compared with separate use, combined backwashing with air and water at an appropriate intensity is more efficient in both pollutant removal and risk reduction. This study is expected to provide some 
useful baseline information for drinking water biofiltration process optimization. Future studies may include in-depth and comprehensive investigations of the optimal operational conditions in biofilters, so as to remove hazardous pollutants and reduce potential public health risk in a more efficient manner.

Acknowledgments This study was financially supported by National Natural Science Foundation of China (No. 50938004 and 51008153), National Major Science and Technology Program of Water Pollution Control and Management of China (2009ZX07210002-003.1) and Science \& Technology Pillar Program of Jiangsu Province, China (BE2011722).

\section{References}

Ahmad R, Amirtharajah A (1998) Detachment of particles during biofilter backwashing. J Am Water Works As 90(12):74-85

APHA (American Public Health Association), AWWA (American Water Works Association), WEF (Water Environment Federation) (2005) Standard methods for the examination of water and wastewater. APHA, Washington DC, USA

Bai Y, Zhang J, Li YF, Gao YN, Li Y (2005) Biomass and microbial activity in a biofilter during backwashing. J Zhejiang Univ Sc B 6(5):427-432

Chien CC, Kao CM, Dong CD, Chen TY, Chen JY (2006) Effectiveness of AOC removal by advanced water treatment systems: a case study. Desalination 202(1-3):318-325

Choi YC, Li X, Raskin L, Morgenroth E (2007) Effect of backwashing on perchlorate removal in fixed bed biofilm reactors. Water Res 41(9):1949-1959

Devi R, Alemayehu E, Kumar A, Mengistie E (2008) Removal of fluoride, arsenic and coliform bacteria by modified homemade filter media from drinking water. Bioresource Technol 99(7): 2269-2274

EMC (Environmental Monitoring of China) Guidelines for organic pollutant monitoring in source water. Accessible at http://www. cnemc.cn/ on 5 Mar 2011

Fazaelipoor MH (2010) Modeling the heat effects in waste air trickling biofilters. Chem Eng J 164(1):139-145

Gonzalez-Perez MM, van Dillewijn P, Wittich RM, Ramos JL (2007) Escherichia coli has multiple enzymes that attack TNT and release nitrogen for growth. Environ Microbiol 9(6):1535-1540

Hassan AA, Sorial GA (2010) Removal of benzene under acidic conditions in a controlled trickle bed air biofilter. J Hazard Mater 184(1-3):345-349

Ifelebuegu AO (2011) The fate and behavior of selected endocrine disrupting chemicals in full scale wastewater and sludge treatment unit processes. Int J Environ Sci Tech 8(2):245-254

Juhna T, Birzniece D, Larsson S, Zulenkovs D, Sharipo A, Azevedo NF, Ménard-Szczebara F, Castagnet S, Féliers C, Keevil CW (2007) Detection of Escherichia coli in biofilms from pipe samples and coupons in drinking water distribution networks. Appl Environ Microbiol 73(22):7456-7464

Kim J (2009) Fate of THMs and HAAs in low TOC surface water. Environ Res 109(2):158-165

Koutsotoli AD, Papassava ME, Maipa VE, Alamanos YP (2006) Comparing Shigella waterborne outbreaks in four different areas in Greece: common features and differences. Epidemiol Infect 134(1):157-162

Lebrero R, Rodriquez E, Martin M, Garcia-Encina PA, Muñoz R (2010) H2S and VOCs abatement robustness in biofilters and air diffusion bioreactors: a comparative study. Water Res 44(13): 3905-3914

Li FZ, Sang JQ, Zhang XH, Wang ZS (2004) Modification on the conventional procedure to measure AOC in drinking water. J Environ Sci China 16(6):996-1000

Li GC, Xia XH, Yang ZF, Wang R, Voulvoulis N (2006) Distribution and sources of polycyclic aromatic hydrocarbons in the middle and lower reaches of the Yellow River. China Environ Pollut 144(3):985-993

Liu XB, Huck PM, Slawson RM (2001) Factors affecting drinking water biofiltration. J Am Water Works As 93(1):90-101

Moll DM, Summers RS, Breen A (1998) Microbial characterization of biological filters used for drinking water treatment. App Environ Microbiol 64(7):2755-2759

NEPAC (National Environmental Protection Agency of China) (2002) Standard method for the examination of water and wastewater. Environmental Science Press, Beijing

Rattanapan C, Kantachote D, Yan R, Boonsawang P (2010) Hydrogen sulfide removal using granular activated carbon biofiltration inoculated with Alcaligenes faecalis T307 isolated from concentrated latex wastewater. Int Biodeter Biodegr 64(5):383-387

Rene ER, Kim JH, Park HS (2008) An intelligent neural network model for evaluating performance of immobilized cell biofilter treating hydrogen sulphide vapors. Int J Environ Sci Tech 5(3): 287-296

Spagni A, Grilli S, Casu S, Mattioli D (2010) Treatment of a simulated textile wastewater containing the azo-dye reactive orange 16 in an anaerobic-biofilm anoxic-aerobic membrane bioreactor. Int Biodeter Biodegr 64(7):676-681

Sun C, Dong Y, Xu S, Yao S, Dai J, Han S, Wang L (2002) Trace analysis of dissolved polychlorinated organic compounds in the water of the Yangtse River (Nanjing, China). Environ Pollut 117(1):9-14

Thompson JD, Higgins DG, Gibson TJ (1994) Clustal-W improving the sensitivity of progressive multiple sequence alignment through sequence weighting, position-specific gap penalties and weight matrix choice. Nucleic Acids Res 22(22):4673-4680

Tian JY, Chen ZL, Yang YL, Liang H, Nan J, Wang ZZ, Li GB (2009) Hybrid process of BAC and sMBR for treating polluted raw water. Bioresource Technol 100(24):6243-6249

UM-BBD (University of Minnesota Biocatalysis/Biodegradation Database). Accessible at http://umbbd.msi.umn.edu/ on 4 January 2011

USEPA (US Environmental Protection Agency) Drinking Water Standards and Health Advisories. Accessible at http://water.epa. gov/action/advisories/drinking/upload/dwstandards2009.pdf on 10 May 2011a

USEPA (US Environmental Protection Agency) Risk Assessment for Chemical Mixtures. Accessible at http://www.epa.gov/hhrp/ quick_finder/chemical.html on $25 \mathrm{Apr} 2011 \mathrm{~b}$

USEPA (US Environmental Protection Agency). Risk Assessment Guidance for Superfund Volume I Human Health Evaluation Manual (Part A). Accessible at http://www.epa.gov/oswer/riskas sess-ment/ragsa/pdf/rags-vol1-pta complete.pdf on 26 Apr 2011c

Wu B, Zhang XX, Zhang XL, Yasun ASJ, Zhang Y, Zhao DY, Ford T, Cheng SP (2009a) Semi-volatile organic compounds and trace elements in the Yangtze River source of drinking water. Ecotoxicology 18(6):707-714

Wu B, Zhao DY, Zhang Y, Zhang XX, Cheng SP (2009b) Multivariate statistical study of organic pollutants in Nanjing reach of Yangtze River. J Hazard Mater 169(1-3):1093-1098

Wu B, Zhang Y, Zhang XX, Cheng SP (2010) Health risk from exposure of organic pollutants through drinking water consumption in Nanjing. China Bull Environ Contam Toxicol 84(1):46-50

Xu SY, Gao XJ, Liu M, Chen ZL (2001) China's Yangtze estuary: II. phosphorus and polycyclic aromatic hydrocarbons in tidal flat sediments. Geomorphology 41:207-217 
Yu X, Zhang XJ, Wang ZS (2002) Biomass examination by lipid-P method for drinking water bio-treatment. Water Wastewater Eng 28(1):1-6

Yu X, Shi X, Wei B, Ye L, Zhang ST (2009) PLFA profiles of drinking water biofilters with different acetate and glucose loadings. Ecotoxicology 18(6):700-706

Yuan SY, Liu C, Liao CS, Chang BV (2002) Occurrence and microbial degradation of phthalate esters in Taiwan river sediments. Chemosphere 49(10):1295-1299

Zhang ZL, Hong HS, Zhou JL, Yu G (2004) Phase association of polycyclic aromatic hydrocarbons in the Minjiang River estuary. China Sci Total Environ 323(1-3):71-86

Zhang XX, Cheng SP, Sun SL, Zhu CJ (2006) Microbial PAHdegradation in soil: degradation pathways and affecting factors. Pedosphere 16(5):555-565
Zhang Y, Zhang XX, Wu B, Zhao DY, Li M, Cui YB, Ford T, Cheng SP (2009) Degradation of benzo(a)pyrene in Yangtze River source water with functional strains. Ecotoxicology 18(6):742-747

Zhang XX, Zhang ZY, Ma LP, Liu N, Wu B, Zhang Y, Li AM, Cheng SP (2010) Influences of hydraulic loading rate on SVOC removal and microbial community structure in drinking water treatment biofilters. J Hazard Mater 178(1-3):652-657

Zheng B, Long TR (2008) Transformation of phosphorus in intermittent aerated biofilter under aerobic continuous feeding with long backwashing intervals. J Hazard Mater 156(1-3):267-276

Zhu LZ, Chen YY, Zhou RB (2008) Distribution of polycyclic aromatic hydrocarbons in water, sediment and soil in drinking water resource of Zhejiang Province. China J Hazard Mater 150(2):308-316 